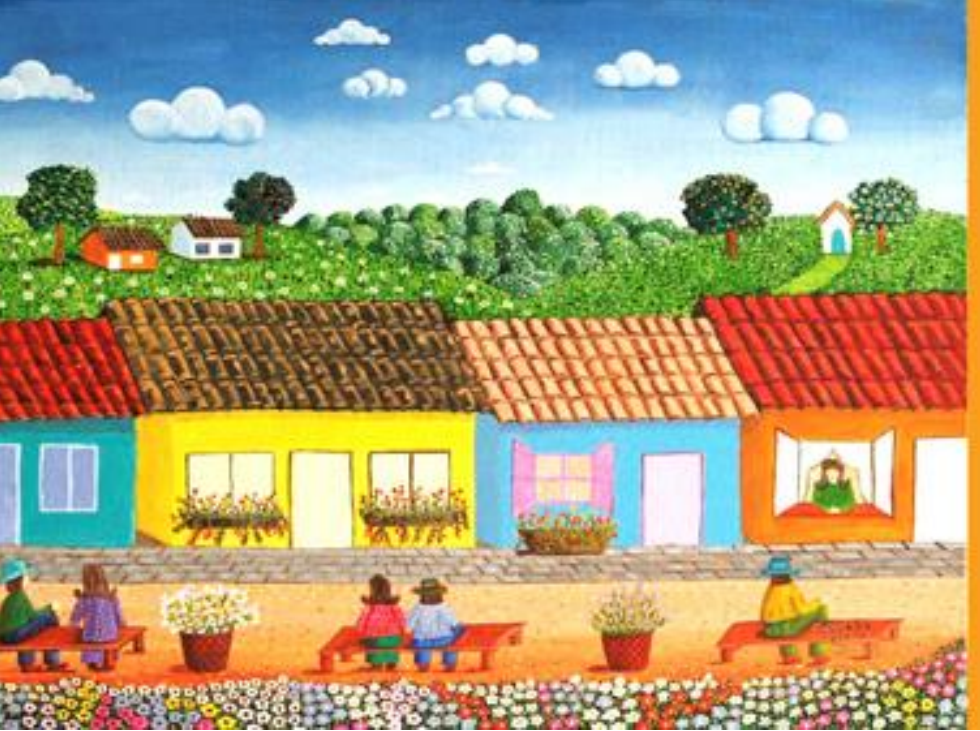

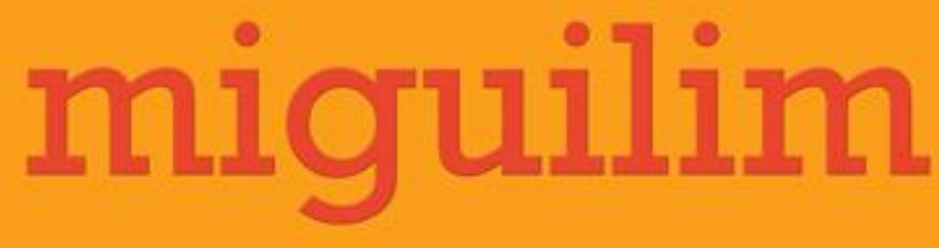

revista eletrônica do netlli

volume 9, número 2, maio-ago. 2020

\title{
ANTONIO CANDIDO E JOSÉ CARLOS MARIÁTEGUI: BREVE ESTUDO COMPARATIVO SOBRE A QUESTÃO DA LITERATURA NACIONAL
}

\section{ANTONIO CANDIDO AND JOSÉ CARLOS MARIÁTEGUI: BRIEF COMPARATIVE STUDY ON THE ISSUE OF NATIONAL LITERATURE}

\author{
Yasmeen Pereira da CUNHA \\ Universidade Federal de Goiás, Brasil
}

RESUMO | INDEXAÇÃO | TEXTO | REFERÊNCIAS | CITAR ESTE ARTIGO | A AUTORA RECEBIDO EM 04/01/2020 APROVADO EM 01/05/2020

\section{Resumo}

O presente artigo tem o intuito de fazer um breve estudo comparativo entre as formulações literárias dos autores Antonio Candido e José Carlos Mariátegui. Tal comparação irá partir do pressuposto metodológico adotado tanto pelo crítico brasileiro, quanto pelo crítico peruano, a saber, o materialismo histórico dialético. Em posse de tal abordagem, ambos os autores analisam o processo de formação das literaturas peruana e brasileira de modo a estabelecer critérios do que chamarão de "literatura nacional". Desse modo, este artigo irá apresentar pontos de semelhança e diferença entre os autores, no intuito de proporcionar uma maior reflexão para a formação das literaturas dos países da América Latina, no sentido de fixar processos inerentes à experiência dessa região do continente, mas também as diferenças próprias de cada país. Quanto ao principal aspecto de similaridade, Candido e Mariátegui 
partem do processo de colonização, sendo essa particularidade histórica a questão decisiva para a compreensão da formação da literatura de países colonizados, como Brasil e Peru. Portanto, pretende-se com tal análise oferecer ao leitor a visão de um autor pouco conhecido, como é o caso de Mariátegui, o qual pode, em comparação com as formulações de Candido, proporcionar novos entendimentos à literatura brasileira.

\section{Abstract}

This article aims to make a brief comparative study between the literary formulations of the authors Antonio Candido and José Carlos Mariátegui. Such a comparison will start from the methodological assumption adopted by both the Brazilian critic and the Peruvian critic, namely dialectical historical materialism. Having such an approach, both authors analyze the process of formation of the Peruvian and Brazilian literatures in order to establish criteria of what they will call "national literature". Thus, this article will present points of similarity and difference between the authors, in order to provide greater reflection for the formation of the literatures of Latin American countries, in order to fix processes inherent to the experience of this region of the continent, but also differences in each country. As for the main aspect of similarity, Candido and Mariátegui start from the process of colonization, this historical particularity being the decisive question for understanding the formation of the literature of colonized countries, such as Brazil and Peru. Therefore, it is intended with such analysis to offer the reader the vision of a little known author, as is the case of Mariátegui, which can, in comparison with Candido's formulations, provide new understandings to the Brazilian literature.

\section{Entradas para indexação}

PALAVRAS-CHAVE: Antonio Candido. José Carlos Mariátegui. Literatura Nacional. Materialismo histórico dialético.

KEYWORDS: Antonio Candido. José Carlos Mariátegui. National Literature. Dialectical historical materialism.

\section{Texto integral}

José Carlos Mariátegui (14 de junho de 1894 - 16 de abril de 1930) foi um escritor, jornalista, sociólogo e militante marxista peruano. Atualmente, é reconhecido como um dos mais importantes pensadores e dirigentes vinculados à tradição marxista-revolucionária. Sua obra foi traduzida para vários idiomas, oportunizando o estudo de sua produção teórico-prática no ambiente acadêmico. No Peru, sua obra é estudada tanto por grupos vinculados à direita, quanto à esquerda. Assim, é tido como uma espécie de ícone da nação, reverenciado quase unanimemente. Apesar de tudo isso, como afirma Leila Escorsim (2006, p. 10), no livro Mariátegui - vida e obra, "ao contrário do que se verifica na maioria dos países da América Latina, a cultura socialista brasileira registra um assombroso silêncio no que diz respeito a Mariátegui, quer do ponto de vista crítico-analítico de sua obra, quer do ponto de vista da publicidade de seus textos". Escorsim também 
menciona que a leitura da obra de Mariátegui poderia enriquecer o debate de dilemas vivenciados pela esquerda brasileira, já que existe entre a realidade do Brasil e do Peru interlocuções possíveis devido a semelhanças.

Embora o foco da análise de Escorsim não seja a produção da teoria estética de Mariátegui, é possível inferir que ainda não existe, no Brasil, uma fortuna crítica consistente sobre o autor peruano, assim como há o silenciamento da cultura socialista brasileira sobre Mariátegui. Tal cenário é diferente quanto ao crítico literário brasileiro Antonio Candido. Sem sombra de dúvidas, Candido é, talvez, o estudioso de literatura mais reconhecido do Brasil, sendo amplamente lido nos cursos de Letras do país. Partindo do método materialista histórico dialético, o objeto de crítica do autor brasileiro em questão é a experiência social e intelectual brasileira, a qual pode ser analisada por meio da representação de obras literárias. Segundo Paulo Eduardo Arantes (1992, p. 21), no livro Sentimento da dialética na experiência intelectual brasileira - dialética e dualidade segundo Antonio Candido e Roberto Schwarz, "Antonio Candido disse que tomaria o seguinte partido metodológico: procurar ver em cada tendência a componente oposta, deixando-se guiar por uma atitude que definia como um certo sentimento dos contrários". Tal pressuposto metodológico também é visto nas formulações críticas literárias de José Carlos Mariátegui, sendo que o autor peruano publicou seu livro mais conhecido, Sete ensaios de interpretação da realidade peruana (2008), no ano de 1928, enquanto Candido só viria a publicar a obra Formação da literatura brasileira - momentos decisivos (2009) em 1959. Apesar dos 31 anos que separam as obras mencionadas, é possível identificar muitas semelhanças entre os autores quando o crítico peruano pensa a formação da literatura de seu país.

Sabendo disso, é pretensão deste artigo estabelecer os pontos de semelhanças entre as formulações dos dois autores destacando, quando for necessário, também suas diferenças. Para isso, será utilizado o método que ambos os autores utilizam, isto é, o materialismo histórico dialético. Segundo essa perspectiva, de modo semelhante ao artista, o crítico literário também é um ser social que possui ideologias específicas do seu tempo histórico e, tendo sua consciência formada por meio de processos sociais, expressa em sua produção crítica as mesmas contradições da sociedade em que vive. Ainda análogo ao artista, o crítico de literatura pode representar essas contradições de modo consciente ou não. Desse modo, serão investigados tais pressupostos na obra já citada de Mariátegui, Sete ensaios de interpretação da realidade peruana (2008), e quanto a Antonio Candido serão abordados os livros: A educação pela noite \& outros ensaios (1989), Literatura e Sociedade (2000) e Formação da literatura brasileira momentos decisivos (2009). O ponto de maior semelhança entre as obras é a análise dos fenômenos literários a partir da experiência da colonização, o que desemboca, consequentemente, no entendimento de que a literatura precisa ter uma expressão nacional. Nos dois autores é recorrente a ideia de que a literatura só pode ganhar uma expressão nacional quando souber assimilar os resquícios do processo colonizador por meio de uma produção literária que, ao mesmo tempo em que não negue tal vínculo histórico, possa superá-lo.

Diante do que foi exposto, portanto, é pretendido por este trabalho fazer uma leitura crítica da teoria estética de Mariátegui, de modo que seja possível 
chegar ao entendimento de como o autor pensa o processo de formação de uma literatura nacional. Somado a isso, tal compreensão pode oferecer mais instrumentos de análise para pensar a literatura brasileira por meio das considerações de Antonio Candido. Assim, a importância deste estudo está em divulgar o autor peruano, ainda pouco conhecido na área acadêmica dos estudos literários, de modo que seja possível estabelecer elos entre as literaturas produzidas na América Latina.

\section{APROXIMAÇõES E DISTANCIAMENTOS POSSÍVEIS ENTRE CANDIDO E MARIÁTEGUI}

Antes de propriamente entrar em contato direto com as obras mencionadas dos autores em questão, é pertinente a retomada dos principais pressupostos da teoria estética marxista, já que ambos utilizam tal metodologia. No "Prefácio" da Contribuição à crítica da economia política (2008), Karl Marx evidenciou a relação entre os aspectos subjetivos da vida humana e as condições materiais de uma determinada época. Com isso, Marx mostrou que em momentos de revolução social há a transformação do fundamento econômico e isso interfere na produção da vida espiritual. Contudo, como pontua Gerard Duménil (2011, p. 213), no livro Ler Marx, é necessário distinguir a reviravolta material das condições econômicas e, de outro lado, a reviravolta das "formas jurídicas, políticas, religiosas, artísticas ou filosóficas, em resumo, as formas ideológicas, nas quais os homens tomam consciência desse conflito e fazem-no estourar". Nesse sentido, a relação que se tem entre condições materiais e formas artísticas está no modo como o homem apreende a realidade e a representa numa pintura, numa escultura ou num poema. Essa representação, portanto, está imbuída de ideologias que correspondem ao momento histórico de determinada produção artística. Desse modo, para analisar um produto artístico é preciso considerar que não se pode julgar um homem "pela ideia que ele tem de si mesmo tanto quanto não se julga uma época de reviravolta por sua própria consciência" (DUMÉNIL, 2011, p. 213). 0 ideal, então, é explicar a consciência a partir das contradições históricas de uma determinada época, dos conflitos sociais e de produção.

Marx, no mesmo livro, tratou de estabelecer os conceitos de base e superestrutura, os quais são fundamentais para o estudo materialista histórico dialético de artefatos que são produtos da consciência social, tal como uma obra de arte. No "Prefácio", Marx afirma categoricamente que a estrutura econômica da sociedade, a qual é constituída de relações de produção, é a base da sociedade e neste alicerce se ergue a superestrutura. Desse modo, tal como explica Tom Bottomore (2012, p. 39), no livro Dicionário do pensamento marxista, a estrutura social não pode ser concebida como unidades produtivas, um conjunto dado de instituições ou condições materiais, "mas como uma soma total das relações produzidas pelos homens ou, em outras palavras, das relações de classe que, entre eles, se estabelecem". Partindo dessa concepção de base, é pressuposto que a sua relação com a superestrutura é bastante complexa. Sabendo disso e antevendo que a determinação da base poderia ser mal compreendida, Marx caracterizou essa 
relação como sendo histórica, desigual e compatível com a eficácia da própria superestrutura. No livro Teorias da mais-valia, Marx afirmou que

[...] para examinar a ligação entre a produção espiritual e a produção material, é acima de tudo necessário compreender a última não como uma categoria geral, mas em sua forma histórica definida. Assim, por exemplo, diferentes tipos de produção espiritual correspondem ao modo capitalista de produção e ao modo de produção da Idade Média. Se a própria produção material não for concebida em sua fase histórica específica, é impossível compreender o que é específico à produção espiritual que a ela corresponde e a influência recíproca de uma sobre a outra. (MARX [s/d] apud BOTTOMORE, 2012, p. 39, grifos do autor).

Essa citação de Marx enfatiza que embora a produção espiritual seja determinada pelas condições históricas, a produção espiritual também exerce influência na produção material. Assim, a superestrutura não é um reflexo mecânico da base, ao contrário, possui uma dinâmica própria. A prova disso é que a produção artística e jurídica se desenvolvem em alguns momentos da história de maneira desigual. A arte grega, por exemplo, tem como pressuposto a mitologia grega, a qual, por sua vez, "é uma forma primitiva de tornar propícias forças naturais que não são bem-compreendidas ou dominadas, de modo que, nas palavras de Engels, essas falsas concepções têm 'um fator econômico negativo como base'" (BOTTOMORE, 2012, p. 39). Essas forças naturais no modo capitalista de produção já são dominadas e, contudo, a arte grega ainda goza de grande estima e ainda representa um modelo. Desse modo, a determinação da base não reduz a arte a fenômenos econômicos, já que a superestrutura possui uma autonomia relativa. 0 sentido da palavra determinação não é a de um processo em que um conteúdo subsequente é essencialmente prefigurado, previsto e controlado por uma força externa pré-existente. Ao invés disso, a determinação da base em relação à superestrutura fixa limites e exerce pressões, isto é, representa as forças externas e as leis internas de um desenvolvimento particular. A totalidade das relações de produção, nesse sentido, constitui uma base econômica da sociedade, a qual se eleva uma superestrutura jurídica e política que, por sua vez, produz formas sociais determinadas de consciência. Assim, "o modo de produção da vida material condiciona o processo de vida social, política e intelectual. Não é a consciência dos homens que determina o seu ser; ao contrário, é o seu ser social que determina sua consciência" (MARX, 2008, p. 49).

Sobre isso, Raymond Williams (2011), no texto "Base e superestrutura na teoria da cultura marxista", argumenta que a superestrutura é uma forma de mediação e algo mais do que a mera reprodução ou reflexo da base. Além disso, a base nunca é, na prática, uniforme ou estática; existem contradições profundas nas relações de produção e nas consequentes relações sociais, ou seja, há a possibilidade constante de variação dinâmica dessas forças. Como as relações de produção e as relações sociais são atividades específicas de homens reais, 
portanto, ativas, dinâmicas e complexas, a base não pode ser imaginada figurativamente como um estado, mas sim como um processo. Para pensar a questão da produção artística de um ângulo que não exclua a relação entre base e superestrutura, mas que também não entenda essa relação de modo mecânico e pré-existente, Williams (2011, p. 43) propõe que "seria preferível que pudéssemos iniciar com a proposição [...] de que o ser social determina a consciência". Isso porque o artista, enquanto ser social, é imbuído de ideologias específicas de seu tempo histórico e, à medida que tem a subjetividade historicamente construída por tais processos sociais, formaliza questões relativas às contradições da sociedade em que vive de modo consciente ou não.

Semelhante ao artista, o processo de elaboração de teoria e crítica literárias também passa, necessariamente, por transformações ocasionadas pelo tempo histórico. Sendo assim, as formulações de Candido e Mariátegui são produtos da consciência formada por meio de transformações sociais específicas. A teoria estética de José Carlos Mariátegui, por exemplo, não pode ser dissociada de sua teoria política. Segundo Mariátegui (2008, p. 223), no livro Sete ensaios de interpretação da realidade peruana, o vínculo entre política e literatura

[...] não quer dizer que considero o fenômeno literário ou artístico de pontos de vista extra-estéticos, mas sim que minha concepção estética é unânime, na intimidade da minha consciência, com minhas concepções morais, políticas e religiosas e que, sem deixar de ser concepção estritamente estética, não pode operar independentemente ou diversamente.

Apesar da crítica literária de Candido não ter a pretensão de imparcialidade, é possível afirmar que esse seja um dos pontos de diferença entre Candido e Mariátegui, uma vez que como aponta Paulo Arantes (1992, p. 10) o posicionamento de Candido é:

[...] em matéria de dialética, melhor praticá-la do que anunciá-la; mencioná-la, ainda que de propósito, é o meio mais seguro de conquistar aliados e fazer adversários sem que o assunto em pauta venha para o primeiro plano de análise e o acordo se faça em função do conteúdo exposto, e não das convicções anteriores.

Até então não é possível afirmar que Antonio Candido tenha sido leitor de Mariátegui. Sabe-se, contudo, que o crítico brasileiro comentou sobre o autor peruano na ocasião em que escreveu sobre Florestan Fernandes, tal como comprova a citação abaixo:

Florestan sempre deu importância capital à fundação da Universidade e da nossa Faculdade. Mas talvez seja meio injusto quando a compara com o movimento modernista. São coisas 
diferentes, com funções históricas diferentes, e não podem ser comparadas como ele faz. Ele fala de modernismo como se fosse uma empresa de cunho político que não correspondeu ao que se esperava; e é sintomático que lembre Mariátegui em detrimento dos nossos escritores daquela vanguarda. Ora, Mariátegui era um político, um militante de esquerda, um líder de alto porte, que era também escritor. 0 seu alvo era outro. Creio que Florestan minimiza a carga específica de fantasia e liberdade criadora que são fundamentais no domínio da arte e da literatura, e que devem constituir a pedra de toque para avaliar movimentos como o modernista, em cujos participantes o papel ideológico e a ação prática são por assim dizer subprodutos. (CANDIDO, 1996, apud RUBBO, 2016, p. 84).

Percebe-se que, diferente de Candido, Mariátegui se nomeia como uma testemunha do processo de elaboração de uma literatura nacional no Peru, buscando ser um agente ativo, o qual pretende discutir de modo consciente esse processo. Por esse motivo, Mariátegui afirma que "minha crítica renuncia a ser imparcial ou agnóstica, caso a verdadeira crítica pudesse sê-lo, coisa em que absolutamente não acredito. Toda crítica obedece a preocupações de filósofo, de político ou moralista" (MARIÁTEGUI, 2008, p. 222). 0 crítico peruano também declara "[...] sem escrúpulos, que aporto à exegese literária todas minhas paixões e ideias políticas, ainda que, dado o descrédito e degeneração desse vocábulo na linguagem corrente, devo agregar que a política em mim é filosofia e religião" (MARIÁTEGUI, 2008, p. 222-223). Vê-se, então, que Mariátegui faz o exercício de compreender a literatura a partir de uma perspectiva muito bem delimitada, a qual perpassa seu ser histórico e subjetivo, posição diversa de Candido.

Embora exista essa diferença entre os autores, é possível estabelecer semelhanças. Para Mariátegui, a literatura peruana deve ser categorizada em três períodos: 1-literatura colonial; 2- literatura cosmopolita; e 3-literatura nacional. Sobre a literatura colonial, o autor peruano diz que:

A primeira etapa da literatura peruana não podia eludir a sorte que lhe era imposta por sua origem. A literatura dos espanhóis da colônia não era peruana; é espanhola. Claro está que não por ser escrita em idioma espanhol, mas sim por ter sido concebida com espírito e sentimento espanhóis. A esse respeito me parece que não existem discrepâncias. Gálvez, hierofante do culto ao vicereinado em sua literatura, reconhece como crítico que "a época da colônia não produziu mais que imitações servis e inferiores da literatura espanhola" [...] (MARIÁTEGUI, 2008, p. 227).

A explicação dada por Mariátegui em relação à literatura no período colonial se aproxima muito do que Antonio Candido (2009, p. 11) afirmou no livro Formação da literatura brasileira - momentos decisivos: 
Cada literatura requer tratamento peculiar, em virtude dos seus problemas específicos ou da relação que mantém com outras. A brasileira é recente, gerou no seio da portuguesa e dependeu da influência de mais duas ou três para se constituir. A sua formação tem, assim, caracteres próprios e não pode ser estudada como as demais, mormente numa perspectiva histórica, como é o caso deste livro, que procura definir ao mesmo tempo o valor e a função das obras.

Além de os dois autores atentarem para a necessidade de estudar as literaturas brasileira e peruana a partir da relação com seus colonizadores, tanto Candido, quanto Mariátegui, afirmam que a literatura produzida no período colonial pode apresentar nomes de autores com grande importância, sem, contudo, formar uma literatura nacional. Para o crítico brasileiro, tal período pode ser explicado por meio do conceito de manifestações literárias, como explica:

Em fases iniciais, é frequente não encontrarmos esta organização, dada a imaturidade do meio, que dificulta a formação dos grupos, a elaboração de uma linguagem própria e o interesse das obras. Isto não impede que surjam obras de valor, - seja pela força da inspiração individual, seja pela influência de outras literaturas. Mas elas não são representativas de um sistema, significando quando muito o seu esboço. São manifestações literárias, como encontramos no Brasil, em graus variáveis de isolamento e articulação [...]. (CANDIDO, 2009, p. 26, grifos do autor).

Mariátegui chega a conclusões muito parecidas em relação a autores específicos da literatura peruana no período colonial. Para o autor, há no período citado duas exceções:

As duas exceções, muito mais a primeira do que a segunda, são incontestáveis. Garcilaso, sobretudo, é uma figura solitária na literatura da colônia. Em Garcilaso se dão as mãos duas idades, duas culturas. Mas Garcilaso é mais inca que conquistador, mais quéchua que espanhol. É, também, um caso de exceção. E nisso reside precisamente sua individualidade e sua grandeza. (MARIÁTEGUI, 2008, p. 228).

Ainda sobre a literatura da colônia, Mariátegui pontua que ela possui determinações muito precisas. Assim, disserta que "nossa literatura não é apenas colonial nesse ciclo por sua dependência e vassalagem à Espanha; é, principalmente, por sua subordinação aos resíduos espirituais e materiais da colônia" (MARIÁTEGUI, 2008, p. 230). Ainda sobre esse período, o autor diz que 
A debilidade, a anemia, a flacidez de nossa literatura colonial $\mathrm{e}$ colonialista provêm de sua falta de raízes. A vida, como afirmava Wilson, vem da terra. A arte tem necessidade de se alimentar da seiva de uma tradição, de uma história, de um povo. E no Peru a literatura não brotou da tradição, da história, do povo indígena. Nasceu de uma importação da literatura espanhola; depois se nutriu da imitação da mesma literatura. Um cordão umbilical doentio a manteve ligada à metrópole. (MARIÁTEGUI, 2008, p. 231).

Sobre o mesmo período, pode-se encontrar um distanciamento quanto à produção literária peruana e brasileira. Assim, é necessário apontar que diferentemente dos literatos peruanos, os escritores brasileiros tinham como missão elaborar uma literatura nacional. Para Mariátegui (2008, p. 232), "O literato peruano quase nunca soube se sentir vinculado ao povo. Não pôde nem desejou traduzir o penoso trabalho de formação de um Peru integral, de um novo Peru". Ao contrário disso, Antonio Candido (2009) afirma que os críticos literários estrangeiros concebiam a literatura do Brasil "como expressão da realidade local e, ao mesmo tempo, elemento positivo da construção nacional" (CANDIDO, 2009, p. 27). Além disso, os escritores do período neoclássico se impuseram a missão de construir uma literatura nacional como prova de que possuíam a mesma capacidade que a dos europeus. Candido afirma que este é o momento da "tomada de consciência dos autores", principalmente no período após a Independência do Brasil. Nota-se, desse modo, um ponto de diferença importante em relação ao processo de elaboração da literatura nacional peruana e brasileira.

Quanto ao período da literatura cosmopolita, Mariátegui define como o momento em que diversos elementos de culturas estrangeiras são assimilados à literatura produzida no Peru. 0 autor que segundo o crítico peruano representa a transição entre período colonial e o cosmopolita é Gonzáles Prada1. Mariátegui afirma que "até Gonzáles Prada o que se considerava peruano nessa literatura ainda não era peruano e sim colonial. O autor de Páginas libres (1985) aparece como um escritor de espírito ocidental e de cultura europeia" (MARIÁTEGUI, 2008, p. 243, grifos do autor). Para Mariátegui, no momento da produção literária de Prada, ainda não existia uma peruanidade definida, contudo, sua literatura anuncia a possibilidade de uma literatura peruana. Desse modo, se configura como uma ruptura com a metrópole e com o vice-reinado. 0 crítico peruano acentua muitas vezes que Prada não representa o povo peruano e nem chegou a elaborar um programa para a geração que viria depois dele. Apesar disso, "representa, de qualquer maneira, um instante - o primeiro momento lúcido - da consciência do Peru. Federico More diz que ele é um precursor do Peru novo, do Peru integral. Mas Prada, a esse respeito, foi mais que um precursor" (MARIÁTEGUI, 2008, p. 243). Isso porque entre as "sentenças alambicadas e retóricas", nas palavras de Mariátegui, em Páginas libres são encontrados germes de um novo espírito nacional. 0 critério fundamental do "germe de um novo espírito nacional" é o fato de Prada não ter desdenhado da "massa". Mesmo sem ter representado o povo peruano em sua totalidade, Mariátegui afirma que o literato em questão preveniu outros escritores sobre a futilidade e a esterilidade de uma literatura elitista. 
Somado a isso, Prada também denunciou o colonialismo. Em relação a tal denúncia,' o crítico peruano argumenta:

Na conferência do Ateneu, depois de constatar as consequências da néscia e senil imitação da literatura espanhola, propugnou abertamente a ruptura desse vínculo. "Abandonemos as andadeiras da infância e busquemos em outras literaturas novos elementos e novos impulsos. Preferimos o espírito livre e democrático do século ao espírito das nações ultramontanas e monárquicas. Voltemos os olhos aos autores castelhanos, estudemos suas obras mestras, enriqueçamos sua linguagem harmoniosa, mas lembremo-nos constantemente de que a dependência intelectual da Espanha significaria uma definida prolongação da infância para nós". (MARIÁTEGUI, 2008, p. 244).

A "infância" a que Prada se refere é a permanência de uma literatura colonial, mera imitação da literatura espanhola. A superação dessa literatura, para Prada, é precisamente o contato com outras literaturas e sua obra representa, particularmente, a influência da literatura francesa, como assegura Mariátegui. Além dessa influência, "sua poesia e mesmo sua prosa acusam conhecimento íntimo com as letras italianas. Sua prosa muitas vezes trovejou contra as academias e os puristas e, heterodoxamente, desfrutou dos neologismos e galicismos" (MARIÁTEGUI, 2008, p. 245). Sobre o período da literatura cosmopolita no Peru, é possível estabelecer elos entre o período mencionado e o Modernismo brasileiro, o qual também se apropriou de novas formas literárias, estrangeiras e formas da literatura popular, em busca da representação de uma literatura "propriamente brasileira". Além disso, a literatura modernista no Brasil foi uma reação às literaturas parnasiana e simbolista, as quais foram categorizadas pelos escritores modernistas como elitistas e pouco representativas da realidade brasileira. Antonio Candido (2000, p. 105), no livro Literatura e Sociedade, argumenta que "o Parnasianismo pouco trouxera de essencial à nossa poesia, apesar do grande talento de Olavo Bilac, Alberto de Oliveira, Raimundo Corrêa ou Vicente de Carvalho". Sobre o Simbolismo, pontua que se limita à obra de Cruz e Sousa e como movimento estético e ideológico "serviu de núcleo a manifestações espiritualistas, contrapostas ao naturalismo plástico dos parnasianos" (CANDIDO, 2000, p. 105). A aproximação entre literatura cosmopolita e Modernismo é também apontada por Bernardo Soares Pereira (s/d), no artigo "Literatura e Questão Nacional em José Carlos Mariátegui”, o qual menciona: "Seguindo a divisão feita por Mariátegui, Retamar ${ }^{2}$ afirma que a fase cosmopolita se iniciaria com o modernismo [...] coincidindo, outrossim, com o momento em que a América Latina adentrava o mundo moderno". (PEREIRA, [s/d], p. 7).

O Modernismo brasileiro, então, foi visto como uma ruptura com um estado de coisas e importava ao movimento, "em sua fase heroica, na libertação de uma série de recalques históricos, sociais, étnicos, que são trazidos à tona da consciência literária" (CANDIDO, 2000, p. 110). Candido (2000, p. 111) também afirma que não se pode ignorar o papel da arte primitiva, do folclore e da 
etnografia na definição das estéticas modernas "muito atentas aos elementos" arcaicos e populares comprimidos pelo academicismo". A relação entre a literatura cosmopolita no Peru e da literatura modernista no Brasil é possível, pois a literatura latino-americana possui especificidades, sendo que a mais evidente é o processo de colonização. Assim como a literatura brasileira, "não cabe aplicar [...] à literatura peruana, categorias [...] que se usam para o estudo de outras que são, essas sim, 'organicamente nacionais e crescidas sem a intervenção de uma conquista'” (ROJO, 2008, p. 20). Em síntese, quanto à literatura cosmopolita, Rojo (2008, p. 24) argumenta que

Isto significa que, depois da dependência de um só centro e antes de ter chegado o escritor à meta tão ansiada da autodeterminação identitária, se terá produzido nele um desprendimento preliminar em relação àquele centro primeiro e exclusivo e sua abertura exploratória para todos os demais. Esse seria, exatamente, o fenômeno que se está consolidando por fim no presente em que Mariátegui vive e escreve. Em desenvolvimento no Peru, a partir das últimas décadas do século XIX, desde Manuel González Prada e os escritores do posterior grupo Colónida, abrir a mente para todos os ventos é a função que terminaram de trazer, nessa inquieta atualidade, as vanguardas. Elas são a antítese que tem que dar, que vai dar, que está dando já (é o que ocorre com César Vallejo, como logo veremos) a oportunidade para o passo seguinte, ou seja, a oportunidade para a síntese.

O esquema dialético apresentado por Rojo diz respeito ao seguinte movimento: literatura colonial (tese) + literatura cosmopolita (antítese) = literatura nacional (síntese). 0 período da literatura nacional é marcado pelo aproveitamento da lição transgressora das vanguardas, somado à influência do passado, de modo a submergir na literatura as impressões próprias do contexto histórico específico. Isso, para Mariátegui, representa a abertura das comportas a uma literatura nacional peruana. 0 escritor que delimita o início desse período é, para o crítico peruano, César Vallejo ${ }^{3}$, o qual "é a alvorada na nova poesia no Peru" (MARIÁTEGUI, 2008, p. 290). Com Vallejo, a literatura produzida no país deixa de ser dependente da herança colonial hispânica ou de quaisquer outras - muito embora seja possível encontrar na poesia de Vallejo elementos das vanguardas europeias - e começa a representar o "Peru integral". Sobre o motivo de o literato peruano mencionado representar a nova etapa da literatura do Peru, Rojo questiona:

Como e por que se produziu com este escritor, neste poeta, e nesta conjuntura precisamente, um salto qualitativo de tamanha magnitude e transcendência? Em primeiro lugar, porque as condições históricas se modificaram e para melhor, porque o entorno social criado por uma época de mudança e efervescência 
peruana, latino-americana e mundial finalmente o autoriza. Logo, porque o talento imenso de Vallejo conseguiu juntar o que ninguém antes dele tinha juntado: conseguiu que em suas obras o fundo e a forma sejam uma e a mesma coisa. (ROJO, 2008, p. 25).

O essencial da atitude literária de Vallejo é, portanto, além de acrescentar novos conteúdos à literatura, criar, para representar tais conteúdos, uma nova forma literária. 0 principal novo conteúdo e o que caracteriza a literatura de Vallejo como nacional é o fato de poder ser encontrado, pela primeira vez, um "sentimento indígena virginalmente expresso. [...] 0 sentimento indígena tem em seus versos uma modulação própria. Seu canto é integralmente seu. Não basta ao poeta trazer uma nova mensagem. Precisa também trazer uma técnica e linguagem novas" (MARIÁTEGUI, 2008, p. 291). Nesse aspecto, é possível estabelecer um ponto de diferença crucial entre a produção literária peruana e brasileira, que é o fato de no Peru ter se mantido, mesmo com a colonização, o quéchua (ou quíchua), que é uma família de línguas indígenas da América do Sul, e também ser, junto com o castelhano, a língua oficial do país. É importante destacar, contudo, que Mariátegui tem consciência de que a utilização por Vallejo do quéchua não nega a filiação espanhola da literatura nacional peruana. Sobre isso, o crítico pontua:

\begin{abstract}
A literatura nacional é, no Peru, como a própria nacionalidade, de inegável filiação espanhola. É uma literatura escrita, pensada e sentida em espanhol, ainda que nas tonalidades, e mesmo na sintaxe e na prosódia do idioma, a influência indígena seja, em alguns casos, mais ou menos clara e intensa. [...] A escrita e a gramática quéchuas são, na sua origem, uma obra espanhola, e os escritos quéchuas pertencem totalmente a literatos bilíngues como El Lunarejo, até o aparecimento de Inocencio Mamani, o jovem autor de Tecuípac Munashcan. A língua castelhana, mais ou menos americanizada, é a linguagem literária e o instrumento intelectual dessa nacionalidade, cujo trabalho de definição ainda não se concluiu. (MARIÁTEGUI, 2008, p. 226, grifos do autor).
\end{abstract}

Sem negar, portanto, o vínculo com a filiação espanhola, Mariátegui determina que para a produção de uma literatura nacional no Peru é fundamental que o quéchua seja representado esteticamente. Por esse motivo, Vallejo é o máximo representante desse período, pois o mais fundamental e característico de sua arte é a presença do elemento indígena. Para o crítico literário peruano, a poesia de Vallejo apresenta

[...] um americanismo genuíno e essencial. Não um americanismo descritivo e localista. Vallejo não recorre ao folclore. A palavra quéchua, o fraseado vernáculo não se insertam artificialmente em sua linguagem. São nele o produto espontâneo, célula própria, elemento orgânico. Poder-se-ia dizer que Vallejo não escolhe seus vocábulos. Seu autoctonismo não é deliberado. Vallejo não se 
afunda na tradição, não se interna na história para extrair de seu substrato obscuro emoções perdidas. Sua poesia e sua linguagem emanam de sua carne e de sua alma. Sua mensagem está nele. 0 sentimento indígena atua em sua arte sem que ele o saiba ou queria. (MARIÁTEGUI, 2008, p. 293).

Quando Mariátegui utiliza os termos "espontâneo" e "elemento orgânico" quer indicar que a representação do elemento indígena faz parte do modo como o escritor apreende a realidade social do Peru e entra em contato com a tradição literária do país não para repeti-la, mas para criar algo novo por meio dela. Tal apreensão seria o caminho para a superação da dependência da literatura peruana. Nesse ponto é possível identificar um aspecto de semelhança muito importante entre Mariátegui e Candido. No livro A educação pela noite \& outros ensaios (1989, p. 153), o crítico brasileiro apresenta o conceito de causalidade interna, ou seja, a capacidade de escritores brasileiros em "[...] produzir obras de primeira ordem, influenciada, não por modelos estrangeiros imediatos, mas por exemplos nacionais anteriores". Candido cita como exemplo os poetas das gerações de 1930 e 1940, os quais tomam como modelo os autores modernistas, os quais, por sua vez, tiveram como modelo as vanguardas europeias. Nesse sentido, é possível enxergar que o processo de consolidação de uma literatura cosmopolita do Peru é próximo ao que acontece no Brasil nas décadas de 1930 e 40.

Vale comentar, ainda sobre a literatura cosmopolita, que Mariátegui postula uma diferença fundamental entre literatura nacional e vertente nacionalista. Quanto à vertente nacionalista na literatura, o crítico peruano afirma ser um fenômeno de pura raiz política: “O 'nacionalismo' na historiográfica literária é, portanto, um fenômeno com a mais pura raiz política, alheio à concepção estética da arte" (MARIÁTEGUI, 2008, p. 225). Portanto, a figuração literária do quéchua se torna um elemento fundamental da literatura nacional, uma vez que integra a unidade política e social do Peru. Sabendo isso, é importante definir o conceito de nação para Mariátegui. Sobre isso, Rojo (2008, p. 18-19) argumenta:

[...] a nação não é para José Carlos Mariátegui, como para tantos de seus predecessores e contemporâneos, um substrato essencial, feito de uma vez e para sempre, por não se sabe por quais poderes sobrenaturais, e que assim determina tudo quanto acontece na história. É, pelo contrário, obra da história mesma. É o produto da imaginação e do esforço de indivíduos históricos concretos, dependente, por conseguinte, das lutas e avatares que em seus respectivos contextos esses indivíduos realizam para satisfazer suas aspirações fundamentais e que não são outras que as de se desenvolver em um tipo de comunidade moderna, livre e horizontal ao mesmo tempo, que lhes dê a todos e a cada um a oportunidade de encontrar o melhor lugar para o exercício de suas habilidades. 
O conceito de nação de Mariátegui se aproxima muito da definição de cultura nacional de Frantz Fanon. Em Os condenados da terra, Fanon (1968) estabelece relações entre uma cultura nacional e as lutas de libertação de nações que foram colonizadas. 0 marxista francês assegura que o domínio colonial, sendo total e simplificador, promove a desarticulação da existência cultural de um povo subjugado. Esse apagamento cultural ocorre porque há a negação da realidade nacional, somado às "[...] novas relações jurídicas introduzidas pela potência ocupante, o lançamento à periferia, pela sociedade colonial, dos indígenas e seus costumes, a usurpação, a escravização sistemática dos homens e das mulheres" (FANON, 1968, p. 197). Tanto para Fanon, quanto para Mariátegui, a luta por uma cultura nacional configura a luta contra o domínio do colonizador. Por esse motivo, Mariátegui é insistente ao afirmar que a literatura peruana, em seu período colonial, não pode ser considerada uma literatura nacional, já que "não há, não poderia haver, cultura nacional, vida cultural nacional, invenções ou transformações culturais nacionais no quadro de um domínio colonial" (FANON, 1968, p. 198). A literatura peruana da colônia, portanto, não é representativa do "Peru integral", como o crítico peruano várias vezes se refere. Ainda estabelecendo relações entre Mariátegui e Fanon, a literatura cosmopolita, apesar de reivindicar uma literatura não elitista, ainda não é nacional. Contudo, a literatura produzida nesse período figura como

[...] tentativas ousadas de reativar o dinamismo cultural, de reorientar os temas, as formas, as tonalidades. 0 interesse imediato, palpável, evidente de tais sobressaltos é nulo. Mas, enquadrinhando as consequências até seu limite máximo, percebemos que se prepara uma desopacização da consciência nacional, um reexame da opressão, uma abertura para a luta de libertação. (FANON, 1968, p. 198).

A luta por libertação mencionada por Fanon é evidente no pensamento de Mariátegui quando o crítico peruano ressalta a obrigação que a literatura nacional no Peru tem de representar o quéchua. Essa representação é o indício de que os esforços que os colonizadores tiveram em inferiorizar uma cultura foram, finalmente, superados. Essa superação, contudo, não é feita por meio da produção literária, mas pela luta dos povos colonizados, os quais diante das contradições inerentes do sistema colonialista reforçam sua combatividade e promovem uma consciência nacional. Sobre o processo de transição para uma cultura nacional, Fanon (1968, p. 200) argumenta que

De fato, o progresso da consciência nacional no povo modifica e precisa as manifestações literárias do intelectual colonizado. A coesão continuada do povo constitui para o intelectual um convite a ultrapassar o grito. A queixa faz frente ao requisitório e depois ao apelo. No período seguinte aparece a palavra de ordem. A cristalização da consciência nacional vai ao mesmo tempo transtornar os gêneros e os temas literários e criar 
completamente um novo público. Enquanto a princípio o intelectual colonizado produzia pensando exclusivamente no opressor, ou para fasciná-lo ou para denunciá-lo através de categorias étnicas ou subjetivistas, pouco a pouco o hábito de se dirigir a seu povo.

0 "hábito de se dirigir a seu povo" de Fanon é muito semelhante à qualidade principal que Mariátegui atribui a Vallejo, isto é, a representação do quéchua em sua obra poética. Percebe-se, desse modo, que Mariátegui propõe uma teoria estética que estabeleça relações fundamentais entre a vida concreta e a vida subjetiva, assim como Antonio Candido. É de suma importância compreender as formulações literárias do crítico peruano por meio da colonialidade característica do Peru e de vários outros países da América Latina, como é o caso do Brasil. Por esse motivo, não é coincidência que seja possível encontrar elos entre a formação da literatura peruana e brasileira, uma vez que o Brasil também foi vítima de uma colonização que subjugou as populações indígenas.

\section{CONSIDERAÇÕES FINAIS}

O breve estudo comparativo proposto por este artigo não tem a pretensão de introduzir a leitura de José Carlos Mariátegui a partir da sombra de Antonio Candido. É evidente, contudo, que há entre os dois autores semelhanças que são muito produtivas para pensar de modo crítico a formação da literatura de um país. Além disso, vale ressaltar que foi abordada, apenas, uma das várias obras de Mariátegui que falam sobre literatura. 0 crítico peruano possui uma vasta produção de crítica literária, sendo que a maior parte dessa produção não foi traduzida para o português. Temos, como exemplo, as obras: El artista y la época (1959), Invitacion a la vida heroica - antologia (1989), Literatura y estética (2007), Ensayos literarios - sobre Joyce, Breton y las vanguardias europeas (2012) entre outras. Apesar de o espanhol não ser um idioma que causa tanta dificuldade como outras línguas, o problema está no fato de que, mesmo no idioma original, as obras sobre literatura de Mariátegui não circulam no Brasil. Assim, deve-se entender a proposta deste artigo como um pontapé inicial para destacar a importância do crítico peruano, compreendendo que se trata de um pensamento singular ainda pouco estudado no cenário brasileiro.

\section{Notas}

${ }^{1}$ Gonzáles Prada (05 de janeiro de 1844 - 22 de julho de 1918 - Lima, Peru) foi um escritor, político, anarquista, crítico literário e diretor da Biblioteca Nacional do Peru.

${ }^{2}$ Referência ao poeta e ensaísta cubano Roberto Fernández Retamar. 
${ }^{3}$ César Vallejo (16 de março de 1892 - 15 de abril de 1938 - Santiago de Chuco, Peru) foi um poeta de tendência vanguardista peruano. Também foi contista, romancista, dramaturgo e ensaísta.

\section{Referências}

ARANTES, Paulo. O sentimento da dialética na experiência intelectual brasileira. Rio de Janeiro: Editora Paz e Terra, 1992.

BOTTOMORE, Tom. Dicionário do pensamento marxista. Rio de Janeiro: Zahar, 2012.

CANDIDO, Antonio. Literatura e Sociedade. 8. ed. São Paulo: T. A. Queiroz, 2000; Publifolha, 2000.

A educação pela noite \& outros ensaios. São Paulo: Editora Ática, 1989.

. A Formação da literatura brasileira - momentos decisivos 1750 - 1880. São Paulo/ Rio de Janeiro: FAPESP/ Ouro sobre Azul, 2009.

DÚMENIL, Gerard. Ler Marx. In: Gerard Dúmenil; Michael Löwy; Emmanuel Renault. Trad. Mariana Echalar. São Paulo: Editora Unesp, 2011.

ESCORSIM, Leila. Mariátegui: vida e obra. São Paulo: Expressão Popular, 2006.

FANON, Frantz. Os condenados da terra. Rio de Janeiro: Civilização Brasileira, 1968.

MARIÁTEGUI, José Carlos. El artista e la época. Lima: Editora Amauta, 1959.

. Ensayos literarios - sobre Joyce, Breton y las vanguardias europeas. Buenos Aires: Mardulce, 2012. . Invitacion a la vida heroica - antologia. Lima: Instituto de Apoyo Agrario, 1989. Literatura y estética. Caracas: Fundación Biblioteca Ayacucho, 2007. Sete ensaios de interpretação da realidade peruana. 1ạ. ed. São Paulo: Expressão Popular: Clacso, 2008.

MARX, Karl. Contribuição à crítica da economia política. Trad. Florestan Fernandes. 2. ed. São Paulo: Expressão popular, 2008.

PEREIRA, Bernardo Soares. Literatura e questão nacional em José Carlos Mariátegui. Disponível em:

https://repositorio.ufsc.br/bitstream/handle/123456789/134969/Literatura\%20e\%20Quest\%C 3\%A30\%20Nacional\%20em\%20Jos\%C3\%A9\%20Carlos\%20Mari\%C3\%A1tegui\%20\%20Bernardo\%20Soares\%20Pereira.pdf?sequence=1\&isAllowed=y. Acessado em: 04/01/20.

PRADA, Gonzáles. Páginas libres. Caracas: Fundación Biblioteca Ayacucho, 1985.

ROJO, Grínor. Arte, literatura, crítica e revolução em José Carlos Mariátegui. Aletria. Minas Gerais, v. 17, jan-jun., 2008. 
RUBBO, Deni Alfaro. "Nosso irmão mais velho": Florestan Fernandes, leitor de Mariátegui. Lua nova. São Paulo, 99: 79-105, 2016.

WILLIAMS, Raymond. Base e superestrutura na teoria da cultura marxista. In: Culturae materialismo. São Paulo: Editora Unesp, 2011. p. 43-68.

\section{Para citar este artigo}

CUNHA, Yasmeen Pereira da. Antonio Candido e José Carlos Mariátegui: breve estudo comparativo sobre a questão da literatura nacional. Miguilim - Revista Eletrônica do Netlli, Crato, v. 9, n. 2, p. 174-190, maio-ago. 2020.

\section{A autora}

Yasmeen Pereira da Cunha é graduada em Letras - Licenciatura em Português pela Universidade Federal de Goiás. Mestre em Letras e Linguística, concentração em Estudos Literários, pela UFG. Doutoranda em Estudos Literários também pela UFG. 